\title{
Statistical Analysis of MicroRNA as Markers for Screening of Colon Cancer
}

\author{
Farid E Ahmed* \\ GEM Tox Labs, Institute for Research in Biotechnology, USA
}

Submission:February 9, 2018; Published: April 26, 2018

*Corresponding author: Farid E Ahmed, GEM Tox Labs, Institute for Research in Biotechnology, 2905 South Memorial Drive, Greenville, USA, Tel: +1 (252) 864-1295; Email: instresbiotech@yahoo.com

Keywords : Diagnostic screening; Mortality; Fecal occult blood test; Colorectal cancer; Colonoscopy; Polymerase chain reaction; Exosomal; Transcriptomic; Colonocytes; Sigmoidoscopy; Noninvasive; Exfoliated; Cancerous cells; Reverse transcribed; Polyadenylated; Escherichia coli; Seminvasive; Pomegranate juice; Fermented sobya; Probiotic lactobacilli; Lactobacilli

Abbreviations: CC: Colon Cancer; FOBTi: Fecal Occult Blood Test; CRC: Colorectal Cancer; RT: Reverse Transcriptase; qPCR: Quantitative Real-Time Polymerase Chain Reaction; GMOs: Genetically Modified Organisms; MIQUE: Minimum Information for Publication of Quantitative Real-Time PCR Expression; MCA: Melt Curve Analysis; PGJ: Pomegranate Juice; FS: Fermented Sobya; FS: Lactobacilli; PP: Polyphenol

\section{Commentary}

Diagnostic screening can potentially reduce mortality from Colon Cancer (CC) detection because it enhances premalignant detection. The commonly used immunological Fecal Occult Blood Test (FOBTi) screening lacks sensitivity and imposes dietary restriction, resulting in decreased compliance. The Gold Standard for ColoRectal Cancer (CRC) screening "Colonoscopy" --not requiring dietary restriction-- is invasive, often accompanied by abdominal pain, has potential for complications, is not economical, and could also lead to mortality. Therefore, a noninvasive sensitive screen would be a more convenient test.

A screening approach that uses the relatively stable and non degradable micro(mi) RNA molecules when extracted from either the noninvasive human stool, or from the semiinvasive blood samples by currently available commercial kits and manipulated thereafter, would be more preferable than a transcriptomic messenger (m)RNA-, a mutation DNA-, or an epigenetic- or a proteomic-based test. The proposed quantitative miRNA approach utilizes Reverse Transcriptase (RT), followed by a modified Quantitative real-time Polymerase Chain Reaction (qPCR). However, to account for the non measured exosomal miRNAs, a parallel stool or plasma's total miRNAs test needs to be performed, and corrections for exosomal loss are made to ascertain accuracy of results. Ultimately, a chip needs to be developed to facilitate screening, as has been done for the quantification of Genetically Modified Organisms (GMOs) in foods. A miRNA test in human stool or blood samples that meets laboratory performance criteria, and is based on high throughput automated technologies and quantitative expression measurements currently employed in the diagnostic clinical laboratory, would ultimately be introduced to the clinical setting, making a noticeable impact on the prevention of colon cancer.

Stool testing has many advantages over other colon cancer screening tests because it is noninvasive and requires no unpleasant cathartic preparation, formal health care visits, or time away from work or routine activities. Unlike sigmoidoscopy, it reflects the full length of the colorectum and taken samples represent both the right and left colon. Because colonocytes are released continuously and abundantly into the fecal stream, contrary to situation in blood --where it is released intermittently as in FOBT - and transformed colonoctes produce more RNA than normal ones, this natural enrichment phenomenon in stool partially obviates for the need for laboratory technique to enrich for tumorigenic colonocytes. Additionally, because testing can be performed on mail-in-specimens, geographic access to stool screening is unimpeded, makes it preferable than screening in blood.

Although not all of the shed cells in stool are derived from a tumor, current data indicate that diagnostic miRNA gene expression profiles are associated with adequate number of exfoliated stool cancerous cells.. Moreover, the availability of measurable amount of circulating miRNA genes in stool or blood (either cellular or extracellular), by a sensitive quantitative technique such as PCR in spite of the presence of bacterial DNA, non-transformed RNA and other interfering substances, makes accurate quantification of miRNAs feasible, because the high specificity of PCR primers employed in this method overcomes 
screening obstacles, making the number of abnormally-shed colonocytes in stool, or total RNA present in stool, plasma or serum unlimiting. A test that employs miRNA in stool or blood also results in a robust screen, because of the stability of the miRNA molecules. Also, an approach utilizing miRNA genes is more comprehensive and encompassing than that based on the fragile messenger (m) RNA, because it is based on mechanisms at higher control levels. Ultimately the final noninvasive test in stool or blood will include testing of many miRNA genes showing increased and decreased expression, and a chip containing combination of these stable molecules will be produced, simplifying testing.

For mature miRNAs testing, small noncoding RNAs that exhibit little variation in different cell types (e.g., snoRNAs and snRNAs) are polyadenylated and are Reverse Transcribed (RT) in the same way as the small miRNAs, and thus could serve as controls for variability in sample loading and real-time RTqPCR efficiency in stool testing. They are, however, not suited for data normalization in miRNA profiling in blood because they are not well expressed in serum and plasma samples. Therefore, normalization in blood by a plate mean (i.e., mean CT value of all the miRNA targets on the plate), or by using a commonly expressed miRNA targets (i.e., only the targets that are expressed in all samples) can be used to calculate the mean value, would be needed for accurate normalization of the amplification reaction.

Unlike screening for large numbers of mRNA genes, a modest number of miRNAs is needed to differentiate cancer from normal, and unlike mRNA, miRNAs in stool and blood remain largely intact and stable for detection. Therefore, miRNAs are better molecules to use for developing a reliable noninvasive diagnostic screen for colon cancer, since:

I. The presence of Escherichia coli does not hinder detection of miRNA by a sensitive technique such as qPCR, as the primers employed are selected to amplify human and not bacterial miRNA genes, and

II. The miRNA expression patterns are the same in primary tumor, or in diseased tissue, as in stool and blood samples.

A parallel test could also be run on the small total RNA obtained from noninvasive stool or seminvasive blood samples, and the appropriate corrections for exosomal loss can be made after the tests are carried out, to account for exosomal RNAs.

To screen several miRNA genes using PCR technology, a sequence-specific stem-loop RT primers designed to anneal to the 3'-end of a mature miRNA, followed by a SYBR Green $\AA$ based real-time qPCR analysis "TaqMan ${ }^{\circledR}$ PCR" method is often employed, using an appropriate normalization standard, or in some cases against several standards because the total input amount may vary from sample to sample.

To ensure that miRNA quantification is not affected by the technical variability that may be introduced at different analysis steps, synthetic nonhuman spike-in miRNA may be used to monitor RNA purification and RT efficiencies. QC procedure, known as Minimum Information for Publication of Quantitative Real-Time PCR expression (MIQUE) is implemented to ensure uniformity, reproducibility and reliability of the PCR reaction and data integrity. Statistical analysis is used for data interpretation. Our group used Melt Curve Analysis (MCA) for interpretation of mild nutrogenomic miRNA expression data in a three week dietary intervention trial, by measuring the magnitude of the expression of key miRNA molecules in stool of 25 healthy human adults, following intake of Pomegranate Juice (PGJ), functional Fermented Sobya (FS), rich in potential probiotic lactobacilli, or their combination, in which total small RNA was isolated before and following dietary intake.



Figure 1a: It shows control genes. 


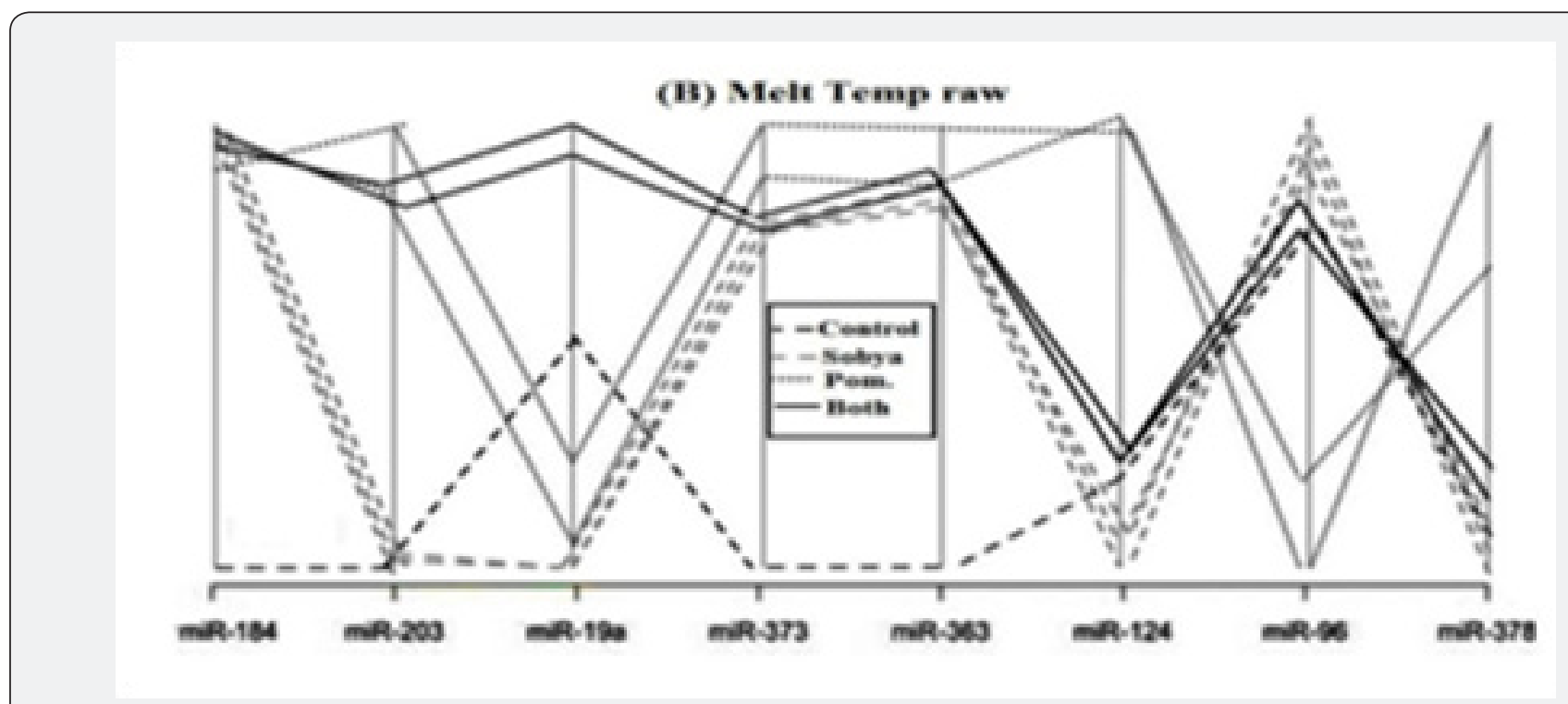

Figure 1b:The five miRNA genes show separation.

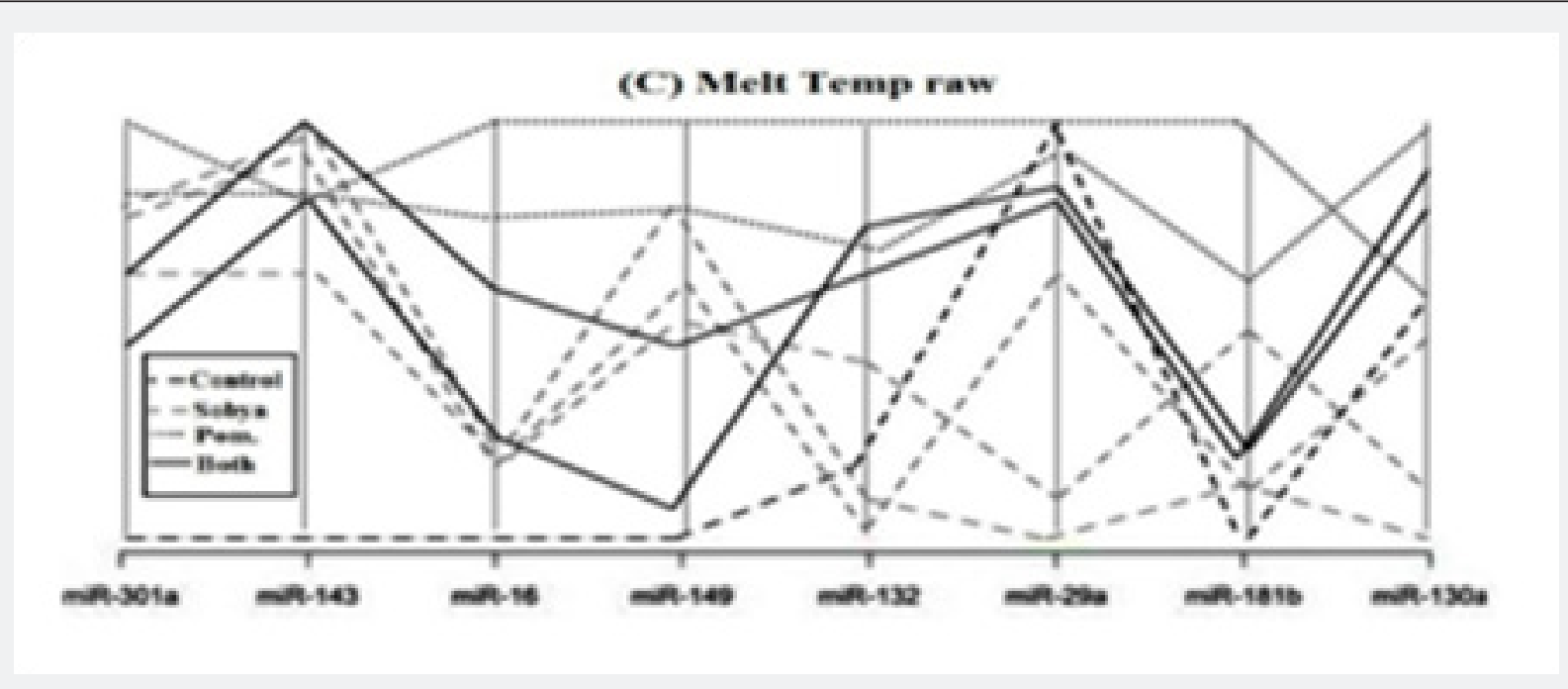

Figure 1c:The five miRNA genes show separation.

Expression of 88 miRNA genes was evaluated, using Qiagen's 96 well plate RT2 miRNA qPCR arrays. Employing parallel coordinate's plots, no observed significant separation was observed for the gene expression (Cq) values, using Roche $480 \AA$ PCR Light Cycler instrument, and none of the miRNAs showed significant statistical expression after controlling for the false discovery rate. However, MCA PCR profiles, identified seven significant genes (miR-184, miR-203, miR-373, miR-124, miR96, miR-378 \& miR-301a), which separated candidate miRNAs, whic could function as novel molecular markers of relevance to oxidative stress and immunoglobulin function, for the intake of Polyphenol (PP)-rich, functional fermented foods rich in lactobacilli (FS), or their combination (Figure 1a-1c), which is a graphical representation of the parallel plot coordinates of the studies miRNA genes. The genes were ordered using the p-values of a one way ANOVA based on groups. Genes with the smallest p-values are presented first. Figure 1a below shows control genes, while in Figures $1 \mathrm{~b} \& 1 \mathrm{c}$, five miRNA genes show separation. 

(C) C) This work is licensed under Creative

DOI: 10.19080/BBOAJ.2018.06.555691

\section{Your next submission with Juniper Publishers} will reach you the below assets

- Quality Editorial service

- Swift Peer Review

- Reprints availability

- E-prints Service

- Manuscript Podcast for convenient understanding

- Global attainment for your research

- Manuscript accessibility in different formats

( Pdf, E-pub, Full Text, Audio)

- Unceasing customer service

Track the below URL for one-step submission https://juniperpublishers.com/online-submission.php 